\title{
ENSAYOS
}




\section{EL CONVENTO COMO CASA DE ESTUDIOS EN EL NUEVO REINO DE GRANADA \\ $15631604^{*}$}

Stella Restrepo de Martínez**

A la lectura de cátedra debe el convento su consolidación como "Casa de Estudios" en el Nuevo Reino de Granada. El acontecimiento en cuestión deslinda las posiciones de los eclesiásticos seculares y regulares frente a la Evangelización; caracteriza sus propias instituciones y delimita la participación de los saberes.

Desde diversos puntos de vista se había hablado de la reunión de sujetos para ser enseñados, sin que práctica alguna hubiese logrado sacar el ejercicio de las letras del discurso de la Evangelización. Los intentos de formar "Escuelas para hijos de Caciques"; para adoctrinar los hijos de conquistadores y vecinos de los principales pueblos, como de dar formación al clero y religiosos por parte de la Corona, eran propuestas ligadas a la política de enseñar en lengua castellana; y designaban la "Escuela de Primeras Letras" como la primera institución a establecer en nuestro país. Pero los acontecimientos de la Evangelización desbordan las políticas de mediados del siglo XVI y sitúan los estudios mayores como la primera actividad regular de las letras coloniales.

Por su parte, el discurso religioso dominante como estrategia en la legislación vigente en el período señalado, apunta a la moral como blanco. Las costumbres de la población y de los eclesiásticos ocupan el plano principal de las tareas a desarrollar por autoridades locales y metropolitanas que para llevarlas a cabo encuentran la necesidad de reformar lo legislado respecto al ejercicio de la lengua. A partir de ella, tiene lugar la elección de la moral como saber que inaugura el funcionamiento de seminarios y casas de estudio.

\section{La lectura de cátedra}

La lectura de cátedra en nuestros colegios mayores coloniales se constituyó en la práctica de saber por excelencia. El catedrático partiendo de un texto o de la composición elaborada por él anteriormente, leía apartes a "viva voz". La lectura de cátedra fue el resultado de un proceso de selección y orden de autores y partes de las obras respectivas para impartir bis-tracción a miembros de una comunidad o estudiantes de seminarios y colegios mayores en los siglos XVII y XVIII.

El autor era el principio de autoridad por encerrar dentro de sus obras los alcances de una teoría o doctrina, en la cual se inscribían las verdades teológicas o dogmáticas de las que participaban las órdenes religiosas. En el autor estaba la "clave" para pensar y llegar al entendimiento. Por eso jurar al autor equivalía a manifestar la adhesión a una doctrina y reconocer-se perteneciente a una posición de fe a modo de miembro de un partido.

\footnotetext{
* Este artículo hace parte de las elaboraciones desarrolladas en la investigación "Los Jesuitas como maestros". Proyecto articulado al programa "Historia de la Práctica Pedagógica en Colombia" que desarrollan las Universidades de Antioquia, Nacional, Pedagógica Nacional y del Valle, con la coordinación general y dirección metodológica de la primera y la cofinanciación de —COLCIENCIAS-.

${ }_{* *}$ Profesora Asistente. Facultad de Ciencias Humanas, Universidad Nacional, Bogotá.
} 
Las obras pertenecientes a un autor o a varios de los elegidos, se constituían en el lugar de dominio y a la vez en el límite para conocer. Allí estaba el cuerpo de los estudios y la propia complejidad por la que éstos debían discurrir.

En los estudios, el autor era puesto en circulación mediante la lectura de apartes de sus propias obras; a partir de interpretaciones comúnmente denominadas "Tratados" o con las composiciones hechas por los catedráticos. Sin embargo la forma de ejercicio sobre los autores y obras fue lo que diferenció la enseñanza de conventos, casas de estudio y colegios mayores especialmente en el siglo XVII y XVIII en el Nuevo Reino de Granada. Una cierta actividad de las letras que se dirigió desde la lectura de cátedra, precisó el trabajo en los colegios mayores respecto a su función docente, distinguiéndolos de las "Casas de Estudio". En los primeros, la lectura de cátedra particularizó los deberes de catedráticos y alumnos; marcó el tiempo de los cursos y la utilidad académica de las bibliotecas.

"La lectura de cátedra" fue un hecho que comprometió la actividad de las iglesias metropolitanas en la época colonial cuando ellas eran lugar donde residía el arzobispo u obispo con su cabildo. En dichas iglesias, —como la Santa $\mathrm{Fe}$ - uno de los prebendados ejercía desde el púlpito la facultad de leer o enseñar a los demás. Dentro de las cuatro canongías existentes (magistral, doctoral, penitenciaria y electoral), una de ellas era ocupada por quien tenía el oficio de dar a conocer a los restantes, artículos de fé, "disposiciones de Iglesia", e instrucciones para el gobierno.

El lugar donde la actividad en mención se distinguió inicialmente como práctica de saber, fue en los conventos de religiosos. En los fundados en el siglo XVI en el Nuevo Reino de Granada estaba presente el oficio del lector, especialmente a raíz de la crítica a la evangelización y las disposiciones del Concilio Tridentino para dar disciplina a todos los eclesiásticos. Antes de dicho acontecimiento los conventos eran casas o residencias en las que los religiosos reposaban de sus tareas cada cierto tiempo como lo dice el padre Francisco de la Cruz en "La vida del doctrinero en los días coloniales". En las actas del capítulo provincial de la orden dominicana en 1639 se lee: "Ningún doctrinero puede hacer ausencia de su doctrina veinte y cuatro horas; cuando vinieren a la elección de conventos, salgan tasando el tiempo, de forma que lleguen al convento el día para que están convocados, o la noche antes; y salgan del convento el día siguiente al de la elección; y para confesarse los que tienen el confesor a las tres leguas tienen obligación de volver el mismo día, y si cuatro, cinco o siete, el día siguiente"1

La constitución de conventos y residencias en la mayoría de los casos sucede a la evangelización de sujetos independientes que sólo tienen de institución el crédito de su pertenencia a una orden. Ella se realiza hasta 1557 gracias a la autorización del diocesano o el gobernador previo acuerdo entre religiosos y superiores de la comunidad. Así alcanzan a legitimar fundaciones los franciscanos llegados desde 1509 y los dominicos en 1529. Porque los Agustinos venidos en 1575 no tuvieron que contar con el Arzobispo para fundar sus conventos y los jesuitas radicados en el siglo XVII dependieron para su establecimiento del Consejo de Indias, dadas las disposiciones de Felipe II en 1593 para reglamentar el inicio de dichas instituciones.

El crecimiento de los conventos hasta finales del siglo XVI se explica en la voluntad de ampliación de las propias corporaciones religiosas como en el deseo de participar de la

\footnotetext{
${ }^{1}$ Vida del doctrinero en los días coloniales / Francisco de la Cruz / En: Historia de la Provincia de San Antonio del Nuevo Reino de Granada del Orden de Predicadores / Alonso de Zamora. Caracas, Parra León Hermanos, 1930, Tomo IV, p. 213. 
conquista de las tierras americanas. Antes de que el Concilio Tridentino ${ }^{2}$ estableciera para las órdenes de religiosos los compromisos a que debían atenerse para obtener el reconocimiento oficial de cada casa, la fundación de una nueva no tenía necesariamente que pasar por la sanción de las Congregaciones Generales o Capítulos como sí se hizo a partir del siglo XVII. Entre un grupo de frailes que acreditaban los propósitos misioneros o la administración de los sacramentos frente a su superior, se decidía la creación en cuestión.

La falta de injerencia de la Corona sobre el asunto y la escasa legislación elaborada por las casas regentes, facilita para las tres órdenes llegadas al Nuevo Reino, antes de la Compañía de Jesús, la fundación de un conjunto de residencias que cumplen mínimas funciones frente a la evangelización. Lo característico de ellas es que no encaran orgánicamente las labores de los misioneros. Cada religioso es responsable directo de su papel y también de su atraso. El convento es más que todo apéndice de las tareas misioneras; ente disperso y anónimo frente al poder local y metropolitano. Su ocupación no la constituyen las letras; no exhibe ninguna presencia en este campo.

Es a partir de la lucha entablada con los encomenderos por la posesión de tributos, cuando los conventos comienzan a tener una relativa unidad. Los frailes buscan el amparo de los suyos y fortalecen los vínculos que los ligan frente al conflicto. Los conventos requieren acreditarse como corporaciones para proteger los beneficios de que disfrutan. Las casas o residencias conventuales entran en proceso de jerarquización; ya se designan "mayores" o "principales" algunos de ellos y "menores" o "casas" los demás. En los primeros habitan los frailes más letrados con cierta permanencia y desarrollan entre los vecinos labores caritativas; también se dedican a "funciones de Iglesia" aderezando sus capillas y oratorios.

A la etapa descrita del convento corresponden las aspiraciones por adquirir el estatuto de "provincias" o "distritos" dentro de la orden a que pertenecen. Para ello argumentan la necesidad de dar formación y títulos a sus frailes. Como dice el cronista Zamora aludiendo a los dominicos: "No fuera Orden de Predicadores si después de ayer enviado a los religiosos a sus Prioratos y las reducciones de sus gentiles no se hubiera instituido en ella una casa de estudios en que se leyeran las Facultades de Artes y Theología. Con la lección de Gramática que se había empezado y proseguido desde 1953 avía algunos estudiantes seculares y religiosos que podían entrar a oír estas facultades"3.

De parte del convento de Santo Domingo “...consta que desde el año1571 tuvo estudios públicos de Artes y Filosofía..."4. Del de San Francisco que comenzó a leer un curso de Artes el Padre Fray Pedro Simón en el año 1603; y en el de San Agustín por el mismo tiempo empezó a leer el padre Fray Vicente Mallol "5

La lectura de Artes y Filosofía era el pilar fundamental para la formación de los religiosos tanto en conventos como en Seminarios. La lectura en cuestión correspondía a la

\footnotetext{
${ }^{2}$ El Concilio de Trento fue convocado por Paulo III. Inició sesiones el 13 de Diciembre de 1545.En Marzo de 1547 en Trento bajo el gobierno de Julio II. Finalizó en 1563, durante el mandato de Pío IV. Uno de sus principales objetivos fue el de disciplinar las órdenes religiosas y dar estatuto a los clérigos.

${ }^{3}$ Historia de la Provincia de San Antonio del Nuevo Reino de Granada/ Fr. Alonso de Zamora O.P.// En: Los Estudios Eclesiásticos Superiores / José Abel Salazar. Madrid, Instituto SantoToribio de Mogroviejo, 1946 p. 104.

${ }^{4}$ Historia de la Provincia de San Antonio del Nuevo Reino de Granada 1 Fr. Alonso de Zamora O.P.// En: Los estudios Eclesiásticos Superiores en el Nuevo Reino de Granada José Abel Salazar. Madrid. ,Instituto Santo Toribio de Mogroviejo, 1946. p. 99.

${ }^{5}$ Ibid. P. 100. 
Teología Moral porque la Dogmática estaba reservada para las instituciones universitarias. Estas cátedras sobre la materia dicha eran exhortaciones solemnes que ponían de manifiesto por parte de cada comunidad sus dotes como predicadores y los puntos doctrinales a que adherían. No eran frecuentes ni participaban en ellas un gran número de frailes. Eran más bien la tribuna para los escasos letrados que la orden poseía.

Merecen destacarse las cátedras de los conventos del Rosario y de Santo Domingo por los años en que se realizaron, puesto que aún la indagación sobre el saber de los frailes no era acontecimiento dominante en el discurso de la evangelización. Claro está que dichos estudios eran intermitentes pues "se comenzaba y en pocos días se caía y acababa" 6 . Mientras tanto en los conventos menores de las órdenes señaladas y en los de los franciscanos no tenían presencia las letras de manera pública.

El reordenamiento del convento hasta finalizar la década del 80 es todavía débil; la incapacidad para expresas públicamente su saber no le permite diferenciación clara entre sus tareas misionales y de estudios. Se exhibe sí por parte de los superiores de las órdenes la existencia de un lector, cuando la nómina de quienes integran el convento acompaña las solicitudes al Consejo de Indias para la obtención de dignidades y prebendas.

Al respecto de la lectura interna que para el cargo en cuestión señala un compromiso, no aparece relacionada (en la documentación consultada) con ninguna actividad literaria específica. Se habla de los oyentes vinculados al lector con rezos colectivos, cánticos o con el conocimiento de las reglas de vida en común. La debilidad del convento es reconocida por el arzobispo de Santafé, don Bartolomé Lobo Guerrero. En el informe que sobre el estado de las doctrinas envía al rey, dice "estos religiosos doctrineros y clérigos.., engañan a V.M. con pedir frailes de cartilla para lectores y para ayudar a la conversión de los indios, porque llegados a las Indias no leen ni se ocupan de ella"7.

La lectura interna realizada en los conventos no tenía límites de tiempo ni propósitos específicos frente a la práctica de la evangelización. Por parte del catedrático no significó una elaboración particular, sino en casos excepcionales. Esta situación mantiene al convento en un grado de saber bastante precario - que al no ser modificado les implicaba la pérdida de su importancia frente al trabajo misional. Porque el ejercicio público de las cátedras se constituyó posteriormente en instrumento de dominio para el mismo trabajo de la catequización.

Si bien es cierto que la mayoría de las órdenes de religiosos no vinieron al territorio del Nuevo Reino con la función de enseñar, es preciso recordar que entrado el siglo XVII quien no fuera ganando el derecho a la cátedra pública, perdía sus principales armas para enraizarse como institución doctrinera en el territorio.

\section{Entre la evangelización y las letras}

En el momento en que se regulariza la lectura pública se están estableciendo condiciones para diferenciar el oficio misional y docente. Este acontecimiento significa para las órdenes, características institucionales. La cátedra pública es el ejercicio de saber que contribuye definitivamente a la articulación del convento como al

\footnotetext{
${ }^{6}$ Informe de la Audiencia al Consejo de Indias sobre los Estudios de la Compañía de Jesús A.G.E. Audiencia de Santa Fe, Legajo 247, Folio 2.

7 Informe del Arzobispo Don Bartolomé Lobo Guerrero a S. M. sobre el estado de las regiones. A.G.I. Sección V. Audiencia de Santa Fe. Legajo 247, Folio 2.

Digitalizado por RED ACADEMICA
} 
establecimiento de prácticas características de los estudios. Es en el Nuevo Reino, el período en que la lucha por los privilegios que conllevaban las doctrinas y la administración de los sacramentos, desplaza masivamente a los frailes de las garantías alcanzadas desde la conquista. A partir de las "Nuevas Leyes del Patronato" expedidas en $1574^{8}$ en la conocida Cédula Magna, el desprestigio general de los eclesiásticos domina el panorama de la vida política.

El estado de postración de los eclesiásticos advertido en las informaciones de autoridades civiles y eclesiásticas, pone en cuestión la formación de cada clérigo y el estatuto de cada convento. Los escasos resultados obtenidos en la evangelización, dicen los informes - son motivados por la ignorancia en que se encuentran tanto los seculares como los regulares. Sus palabras sobre la fe no han tocado las políticas de la Corona porque la población es todavía presa de la corrupción y de la idolatría. Es indómita, está dispersa y no se aplica eficientemente a la producción.

El 1o. de junio del año mencionado, la Corona prohíbe expresamente "fundar ni instituir catedral, parroquia, monasterio, hospital, iglesia, sin consentimiento del Rey o de sus autoridades ni instituir ni proveer beneficios ningunos"9. Para obtener la autorización de tales fundaciones, exige que se hagan "con todo detalle". Y al respecto del nombramiento de prelados y frailes para cargos eclesiásticos, "exige que sean presentados los más idóneos y con más méritos"10.

Las medidas provenientes del Concilio Tridentino a la base de las "Nuevas Leyes del Patronato", tienen que ver por parte del papado con la necesidad de disciplinar los religiosos y dar formación a los clérigos; para ello se plantea la concentración de funciones en los obispos. Acogidas por la Corona, los diocesanos son propuestos dentro del Patronato, como el puente entre autoridades civiles y misionales para reorientar su estrategia colonizadora.

Al nacimiento del convento como Institución de saber ayuda decididamente el segundo arzobispo de Santa Fe, Fray Luis Zapata de Cárdena ${ }^{11}$ quien ejerce sus funciones en un período en que la Audiencia se encuentra acéfala. El dicho prelado se constituye en vocero de las leyes nuevas del Patronato. A pesar de no compartir totalmente lo expresado en ellas por el "favoritismo que expresa frente al poder civil", tomaba en sus manos aquellas que eran la base para el logro de su acción pastoral. Las que tenían que ver con el fortalecimiento del Clero secular son fundamento de los puntos programáticos de su gobierno. Con tal dirección tiene que ver la celebración del Concilio Provincial, cuando se realizaba el tercero de Lima en $1583^{12}$; la creación de un Seminario para "criar ministros en virtud y letras"; y las elaboraciones de las Constituciones y Catecismo "para el mejor gobierno de los indios".

\footnotetext{
${ }^{8}$ La Cédula Real del Patronato de I de Junio de 1574. Sucede las Conclusiones de la "Junta Magna" de 1568 , reunida con el fin de poner remedio a la "despoblación y destrucción de las Indias". Se reunieron con Don Felipe II, representantes de los distintos Consejos del Reino y algunos teólogos. Fruto de ella son las "Instrucciones a Toledo, doctrina y gobierno eclesiástico. Datos tomados de la obra Historia de la Iglesia en la América Española.// León Lopetegui. S.J. y Félix zubillaga, S.J. Madrid, Biblioteca de Autores Cristianos, 1965, p. $191-195$.

${ }^{9}$ Historia de la Iglesia en la América Española desde el descubrimiento hasta comienzos del siglo XIX.// Antonio España, S.J. - Madrid, Editorial Católica, 1966, p. 195.

${ }^{10}$ Ibid. p. 195.

1111 Se posesiona en el cargo el 28 de Marzo de 1573. Sucede al Obispo Fray Juan de los Barrios.

1212 El Concilio Limense es un evento de gran importancia en la vida de los eclesiásticos de los países suramericanos durante la Colonia. En el se debatieron ampliamente las políticas del patronato. Resultado de él es el Catecismo de amplia circulación en el Nuevo Reino de Granada.
} 
Durante su permanencia en la silla apostólica (17 años), seculares y regulares se disputan los beneficios, pero el arzobispo toma partido por los primeros con el apoyo de la comunicación real. En 1583 el rey ordenaba que "habiendo clérigos idóneos y suficientes, los proveáis en los dichos cargos doctrinas y beneficios prefiriéndolos a los frailes" ${ }^{13}$. Es así como comienza a despojar a los frailes de sus doctrinas, asignándolas al clero secular. Surgen demandas especialmente de dominicos y franciscanos; el rey revoca lo mandado anteriormente en 1587; el prelado se resiste al cambio, pero tiene que optar finalmente por un camino intermedio; dar doctrinas a los clérigos y dejar muchas todavía a los frailes.

Dictadas las medidas tendientes a impedir la fundación de nuevas instituciones religiosas y sentadas las bases para el despojo de los beneficios, la Corona designa el conocimiento de la "Lengua General" como la herramienta básica para la evangelización. Se trata de una nueva estrategia para organizar la población indígena que contradice la que era vigente desde el gobierno de Carlos V. Por medio de ella se expresaba que "por ser mucha la variedad de las lenguas y habiendo hecho particular examen sobre si aún en la más perfecta lengua se pueden explicar los ministerios de nuestra Santa fé católica, se ha reconocido que no es posible, sin cometer grandes disonancias e imperfecciones por lo cual convendría introducir la lengua castellana"14.

Las disposiciones dadas anteriormente sobre la enseñanza de la lengua castellana habían sido reconocidas como improductivas para inculcar las "santas y loables costumbres pulíticas y christianas". El arzobispo Lobo Guerrero en carta al rey sobre los frutos conseguidos con la enseñanza en muisca, expresaba: “...decirles en nuestra lengua, como desde que se conquistó este Reino se hacía, no era fruto ni servía de más que pronunciar como papagayos o piscazas lo que no entendían ${ }^{15}$. En cambio se ve expresaba el sínodo en 1617" ...cuán fácilmente entran en ella (la doctrina cristiana) enseñándosela en Lengua General del Inga..."16

Las políticas sobre enseñanza de la doctrina en lengua indígena convocan al convento a expresar públicamente el saber que lo respalde en su labor misional. A través del examen debe acreditar su posesión.

Como voluntad común ante la demanda, los conventos se preocupan por dar cuenta de su saber. Que lo poseían lo acredita la existencia de lenguaraces consumados que más adelante acompañaron como intérpretes a los misioneros jesuitas y colaboraron con ellos en la traducción de las voces indígenas para adecuar a ellas los preceptos del catecismo limense y las principales oraciones. Pero a esta habilidad no habían sumado la de poner en lengua mosca las verdades de la fe. Lenguatarios por el entendimiento común entre la población a reducir, no habían poblado el universo del indio con las nociones cristianas; y más que eso, estaban descalificados por las formas de vida de que participaban.

\footnotetext{
${ }^{13}$ Historia de la Iglesia en la América Española. Op. cit. p. 503-504.

${ }^{14}$ Recopilación de Leyes de los Reinos de las Indias.// Carlos V, 1550, Madrid, Quinta Edición, Boix Editor, 1841. Tomo 1. T.I. Lib. VI. Ley 18.

${ }^{15}$ Carta del Arzobispo de Santa Fé, al Rey sobre los grandes frutos obtenidos por los religiosos de la Compañía de Jesús en las doctrinas que les fueron encomendadas. // En: Documentos para la Historia de la Educación en Colombia/. Codificación y nota preliminar de Guillermo Hernández de Alba. Bogotá, Patronato Colombiano de Artes y Ciencias, T.I. 1969. p. 114.

${ }^{16}$ Historia Eclesiástica de Antioquia. Colonia e Independencia/ Javier Piedrahíta. Medellín: Sínodo de Popayán, 1617. p. 70. 
Lobo Guerrero tercer arzobispo de Santa $\mathrm{Fe}^{17}$ ejerce su mandato teniendo como instrumento las disposiciones reales; todos los que "pretendieron ser presentados a las Doctrinas y Beneficios, no sean admitidos sí no supieren la Lengua General en que han de administrar.., y presentaren fe del catedrático que la leyere en que han cursado..." ${ }^{18}$. Después de cuatro años de gobierno, al decir del fiscal de la Audiencia, el arzobispo" había visitado y confirmado casi todo". De su reconocimiento a las doctrinas saca como experiencia que "no pocos doctrineros desconocían las lenguas indígenas" y llama públicamente a la indagación. "Nombró por examinadores a los que eran lenguaraces y no quiso admitir al examen a los cathedráticos de lengua que tenían los conventos" ${ }^{19}$. Entre la nómina de quienes lo presiden tampoco figuró don Gonzalo Bermúdez "clérigo de misa y de buenas costumbres" quien había sido nombrado para leer la lengua de los indios del Reino" con estipendio de 400 pesos por cédula real desde $1853^{20}$.

El examen de Lengua General permite interrogar a los religiosos por sus costumbres; por su capacidad para representar en las voces del "Inga" los preceptos cristianos; por la adopción de prácticas de policía... Los superiores de los conventos recomiendan ante el arzobispo a muchos de sus religiosos para ser examinados; los elegidos se presentan a la prueba y pierden muchas de sus doctrinas; algunas de ellas pasan a manos de la Compañía de Jesús, recién llegada al Nuevo Reino.

La lengua es el instrumento para reconocer el saber religioso y moral de los frailes y, el acontecimiento que promueve la presencia de la "cátedra pública". Ante el desconocimiento de las calidades morales y religiosas de los misioneros éstos anuncian a las autoridades locales y metropolitanas que en sus conventos "mayores" leen Artes y Teología. Al no haber alcanzado un reconocimiento como traductores corrientes de las lenguas de los indios, pasan a situarse "en el orden del discurso e invitan a sus primeras disertaciones públicas sobre Filosofía (dentro de las cuales hablan de moral) y sobre Teología (en que se contienen las verdades de la fÉi).

La Teología Moral como parte del universo de la Ciencia Teológica se introniza en los conventos que por tal motivo adquieren la categoría de "Casas de Estudio". En torno a la palabra del letrado que la pone en circulación toman asiento los frailes para emprender el camino de las letras. El lector como contendor en asuntos de doctrina y predicador en nombre de la orden, encarna la autoridad teórica y un nuevo oficio al interior de las órdenes de religiosos; será en adelante titular en los estudios y principal depositario de las diferencias que su orden guarda frente a las demás.

En este juego del saber en el que participan la Teología Moral y la Lengua General se produce la primera adecuación de las letras en los estudios coloniales. En él la inicial diferenciación entre la práctica misionera y la de los estudios; la caracterización de las

\footnotetext{
${ }^{17}$ Entró a Santa F6 en el año 1599 con algunos padres de la Compañía de Jesús. Partió de la ciudad en 1609, para tomar posesión del arzobispado de Lima.

${ }^{18}$ Novísima Recopilación de las Leyes de España, divididas en XII libros. En que se reforma la recopilación publicada por Felipe II en el año 1567, reimpresa últimamente en el de 1775, Madrid, Imprenta Real, 18051807, T. VI. Lib.I. Ley 30.

${ }^{19}$ Historia de la Provincia de San Antonio. Op. cit. Tomo III. p. 102.

${ }^{20}$ Real Cédula, Ordenanzas y Constituciones para el establecimiento de la Cátedra de Lengua Indígena en la Universidad de Santa Fe // En: Documentos para la Historia de la Educación en Colombia / Codificación y nota preliminar de Guillermo Hernández de Alba - Bogotá, Patronato Colombiano de Artes y Ciencias, T.I. 1969, p. 35-39. 
"Casas de Estudios" y el nacimiento de los colegios. Gracias al acontecimiento se legítima la "Lengua Indígena" como forma de saber, adquiere estatuto de materia para ser enseñada en el Seminario de San Bartolomé desde 1605 y formalización propia en catecismos, cartillas y gramáticas para el entendimiento común o como instrumento de la acción evangelizadora. Mientras tanto la moral como conjunto de nociones sale de la obra seleccionada por Trento y cada orden de religiosos para inaugurar las primeras Constituciones de los colegios y seminarios y en el Nuevo Reino de Granada.

A partir de la "Lectura de Cátedra" —hecho que particulariza los estudios especialmente en el siglo XVII-, el convento se desarrolla como "Casa de Estudios" y paulatinamente va entregando la dirección de las letras a Colegios y Universidades. La creación de ellos - que parte del acontecimiento señalado - amplía y jerarquiza las funciones de las instituciones religiosas, porque su poder no va a separarse de su uso del saber. 